JUAN CAMILO BUITRAGO

DEPARTAMENTO DE DISEÑO

UNIVERSIDAD DEL VALLE

COLOMBIA

JUAN.BUITRAGO@CORREOUNIVALLE.EDU.CO

1. Esta entrevista fue realizada en dos

momentos distintos. El primero sucedió en

Bogotá, el día 24 de febrero del año 2014 y tuvo una duración de 2 horas y 25 minutos.

El segundo momento fue vía Skype estando Rómulo Polo en Bogotá y yo en São Paulo, Brasil. Este ocurrió el 30 de julio del mismo año y tuvo una duraciónw de 1 hora y 15 minutos.

2. Desde finales de los años sesenta, su producción escrita sobre el campo llega fácilmente a media centena de escritos.

3. Guáimaro, Salamina, en el Departamento del Magdalena, es un pueblo ribereño del río Magdalena, a unos $60 \mathrm{~km}$. al sur de Barranquilla.

Cómo citar: BUITRAGO, J. (2018)

Investigar para diseñar. Entrevista concedida por Rómulo Polo a Juan Camilo Buitrago. RChD: creación y pensamiento, 3(4), 1-10. DOI: 10.5354/0719-837X.2018.50229

Revista Chilena de Diseño, RChD: creación y pensamiento Universidad de Chile

2018, 3(4)

http://rchd.uchile.cl

\section{Investigar para diseñar Entrevista concedida por Rómulo Polo a Juan Camilo Buitrago}

\author{
Reseach to design \\ Interview given by Rómulo Polo to Juan Camilo Buitrago
}

Sin pretensiones de alto vuelo, esta entrevista ${ }^{1}$ tributa al principio de lo que Wright Mills (2003) Ilamó "Biografía Social” y que, fue expresada con contundencia por el propio Marx en aquella sentencia del inicio de El 18 Brumario de Luis Bonaparte en 1852 "...Los hombres hacen su propia historia, pero no la hacen a su libre arbitrio, bajo circunstancias elegidos por ellos mismos, sino bajo aquellas circunstancias con que se encuentran directamente, que existen y les han sido legadas por el pasado..." (Marx, 2003, p. 10).

Rómulo Polo es uno de los iniciadores del diseño industrial en Colombia. Seguramente el más prolífico de todos. ${ }^{2}$ Desde finales de la década del sesenta forma parte del grupo de colombianos pioneros en el ejercicio profesional del diseño, ya diferenciado de la práctica de arquitectos y publicistas. Ha sido uno de los promotores más importantes de la institucionalización del diseño en el país. Entre las menciones más sobresalientes que pudiera anotar aquí, y como será tratado en el trayecto de la entrevista, Polo fue el primer colombiano en dirigir el Departamento de Diseño de Artesanías de Colombia (1967-1968), el creador del programa de Diseño Industrial en la Universidad Javeriana de Bogotá en 1976, así como cofundador de la Asociación Colombiana de Diseñadores (ACD) en ese mismo año. Su convicción por el trabajo asociativo lo llevó a liderar el proceso de creación de la Asociación Latinoamericana de Diseño (ALADI) entre 1978 y 1980, año en el que se funda formalmente en Bogotá y Santandercito (Cundinamarca), de la cual, es el primer presidente entre 1980 y 1982. Luego de una década agitada en la que se trabaja por la consolidación de la asociación, Polo organiza la VI ALADI (VI Asamblea, VI Congreso y I Encuentro Latinoamericano de Estudiantes) que se llevó a cabo en Santa Marta, Colombia, en 1993. Desde 1994 se desvincula del proceso.

En general, los temas conversados con Rómulo Polo están muy ligados con las ideas del proceso de la profesionalización del diseño en su país y, con certeza, se convierten en referencias obligadas al momento de emprender cualquier proceso de investigación histórica de la profesión. De la misma forma, estos hechos dejan ver algunos aspectos de la historia de nuestra sociedad.

Juan Buitrago: Rómulo, ¿usted nació en Guáimaro, Magdalena?.

Rómulo Polo: No, nací en Bogotá.

JB: Pero se crió...

RP: Atribuyo mi nacimiento a ese pueblo ribereño del Magdalena, donde viví parte de mi infancia con mis abuelos paternos, años que fueron particularmente gratos y que recuerdo con afecto: Guáimaro. ${ }^{3}$ Fui huérfano de madre muy temprano, y eso me llevó a vivir con ellos. Luego mantuve un vínculo con el pueblo y en general con el Caribe colombiano, porque mi niñez y primera juventud transcurrió en esa zona. He vivido la mayor parte de mi vida aquí, pero no me siento bogotano; mi apariencia es de cachaco, pero mi espíritu es caribe. Además, mis ancestros son santandereanos por 
Figura 1. Rómulo Polo en conversación con Juan Camilo Buitrago. Archivo fotografía: Bibiana Peña

4. La expresión cachaco podría tener por lo menos dos acepciones: en una, desde los bogotanos, los cachacos son aquellos quienes solían vestir y comportarse de "manera decorosa" en sociedad, principalmente, aquellas generaciones nacidas en Bogotá en la primera mitad del siglo XX. Aún hoy, en ciertos círculos, cachaco se relaciona con estar "bien vestido" y/o hablar de "forma refinada". La segunda acepción es la mirada externa que tiene tintes despectivos y que es fundamentalmente construida en las ciudades y regiones de la Costa Atlántica colombiana. En este uso, los cachacos no son solo los bogotanos, sino todo aquel que haya nacido en el "interior del país". Por su parte, la expresión costeño se utiliza en Colombia para denominar los habitantes de su Costa Atlántica y su cultura. En su caso, los santandereanos, son aquellos colombianos nacidos en el Departamento de Santander, zona geopolítica ubicada al nororiente del país que recibió su nombre del apellido del famoso General en la Independencia de la Nueva Granada, Francisco de Paula Santander.

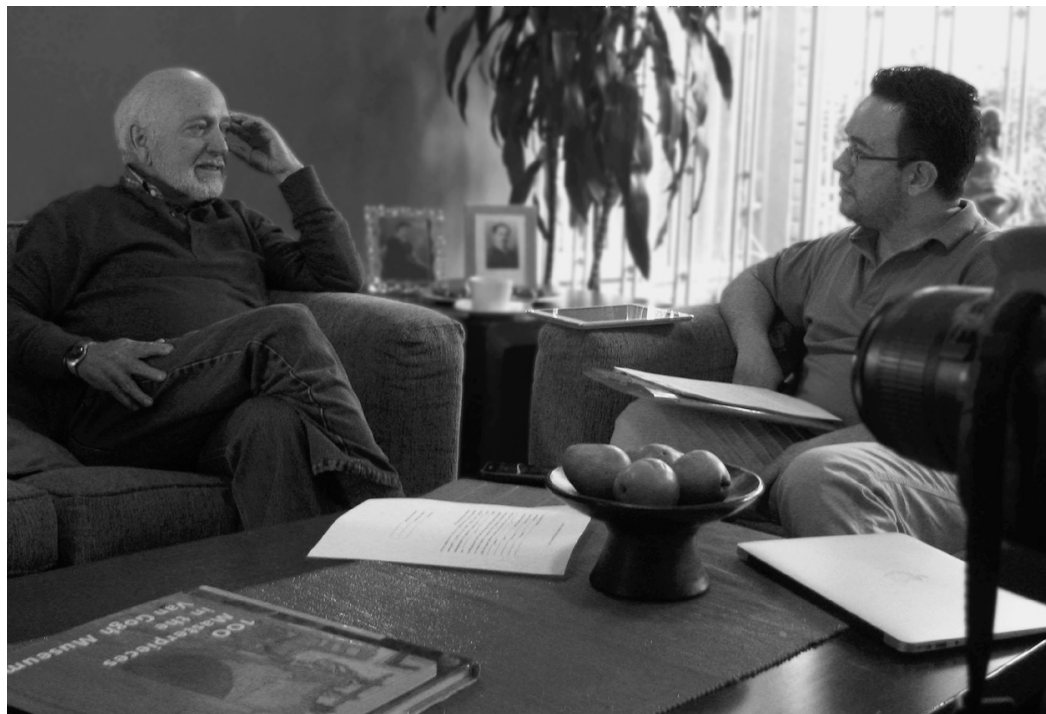

mi madre, y costeños por mi padre. ${ }^{4}$

JB: ¿Cómo era su familia, Rómulo, su madre y su padre, y qué hacían cuando usted era adolescente?

RP: Bueno, como decía, mi madre murió cuando yo era muy niño. Ella era una santandereana de gran vigor. Fue maestra. Una persona muy luchadora, originaria del sur de Santander, de un pueblo andino que se llama Macaravita. Fue líder en su familia y la sacó adelante, poniéndola en el contexto de la ciudad desde mediados a finales de los años treinta aproximadamente. Fue muy católica, con una vocación de servicio muy grande, medio misionera en muchas cosas. El último año de su vida, 1951, lo vivimos en Santa Marta, a donde nos mudamos desde Bogotá, hacia finales de 1949. Ella fue una mujer supremamente activa: allá fundó la llamada "Legión de María” y la gente la recuerda todavía con cierta devoción y mucho afecto, sesenta y tantos años después de muerta... Esa era mi madre. Y mi familia pues, por esa parte, es una familia típicamente santandereana. De hecho parte de los hábitos de mi casa, aquí con Dolly, mi esposa, son santandereanos.

El otro lado es costeño. Mi papá fue doctor en Filosofía y Letras, javeriano, educador, periodista y político en el Departamento del Magdalena. Fue senador a los 30032 años, a finales de los años cuarenta y parlamentario nuevamente entre 1958 y 1962. Mi familia costeña es extensa. Papá también fue una persona con una alta vocación social. Mucha gente aún lo recuerda a pesar de haber muerto hace unos 35 años. Fue muy servicial, e hizo muchas cosas por la región. Se sentía un hombre del río, exactamente de la 'Provincia del Río', como se le decía a la ribera del Magdalena. Me crié en ese contexto, a la orilla de ese gran río. Ahí aprendí a nadar, el valor de las cosas naturales, el aprecio por el folclor y por la gente, el sentir del carnaval, todas esas cosas; el olor del bollo de yuca... cosas fundamentales de la vida.

JB: ¿Y sus padres vinieron a Bogotá... siendo una pareja joven y aquí nacieron ustedes?

RP: No, no. Mi padre vino a estudiar en Bogotá hacia 1938 o 39; mi madre a trabajar desde un poco antes. Se conocieron aquí. Fue una familia de dos hijos. Tengo un hermano de padre y madre. Por el lado paterno, tengo muchos hermanos. Mi mamá murió en 1951 y mi papá murió en 1979. Aquí en Bogotá, 
en la década de los cuarenta, además de hacer su carrera en filosofía, mi papá fue escritor en el periódico El siglo, funcionario del Ministerio de Educación y posteriormente, como dije, se vinculó a la política en su departamento. Un político conservador.

JB: ¿En qué colegio estudió, Rómulo?

RP: ¡Esa es una historia larga! Estudié en 18 colegios. Me gradué en el Colegio Agustiniano de Bogotá en 1964, pero estudié en varios sitios del país... Eso me dio una perspectiva de la vida muy particular, porque, por circunstancias de la viudez de mi padre y de la atención de sus cosas tuvimos que estar moviéndonos. Estuve en Santa Marta, en Pamplona, en Barranquilla, en Guáimaro, estuve en Bogotá desde luego... estuve en muchos colegios.

JB: ¿Y que otro colegio recuerda además del Agustiniano?

RP: Recuerdo con mucha nitidez la Escuela Pública de Guáimaro, por su enseñanza muy particular, integrada. Desde luego incluía castigos de regla por las equivocaciones: había que poner la mano para que le dieran por no saber, o equivocarse. Ayer justamente recordaba con alguien las cosas que de niño me impresionaron de aquella escuela. Por ejemplo, los exámenes finales de año eran con jurado público y el presidente del jurado era mi abuelo. Eso para mí era de una severidad jtremenda!, además, porque soy el tercer Rómulo de la saga de los Polo. Mi abuelo, mi padre y yo tenemos el mismo nombre, y eso me imprimía cierta responsabilidad. También recuerdo La Presentación, en Santa Marta, con las monjas; un recuerdo más vago de Pamplona pues era realmente muy pequeño, pero recuerdo en particular con afecto mis pasos (en algunos casos muy breves... de pocos años, meses o semanas) por el San José, el Biffi, el Colegio Barranquilla, el Panamericano... en fin, fueron muchos. También estudié en el Colegio de la Universidad Libre, en Barranquilla, eso fue un momento interesante para mí, por las dinámicas sociales de la época.

JB: ¿Y esto que me contaba de Guáimaro fue en su niñez o adolescencia? RP: Mi infancia y partes de la adolescencia. De cuarto de primaria a primero de bachillerato estuve en un colegio muy querido por mí, el Gimnasio Santa Marta, del profesor Rafael Gregorio Núñez. Tenía una enseñanza singular. Recuerdo las clases de griego y latín que me han servido mucho, así como la figura del 'viejo Núñez' (como le decíamos), alto, delgado, quien vestía siempre de lino blanco, elegante... era un vallenato sanjuanero de cultura y finura excepcionales.

JB: Y después vuelve a Bogotá, se gradúa...

RP: Hay muchos viajes... muchos ires y venires. Por ejemplo, estuve en el Colegio Camilo Torres, de Bogotá, en segundo y tercero de bachillerato; lo recuerdo también con mucho afecto: aún recuerdo algunos amigos entrañables de aquella época. Todo ese movimiento me dio una pluralidad de visiones $y$, bueno, el hecho de siempre ser el nuevo, eso tiene una connotación especial.

JB: Y se gradúa y estudia Arquitectura en la Universidad Nacional.

RP: Tuve el dilema de contradecir la visión de mi padre sobre lo que debía hacer en la vida. Él era javeriano, como sus hermanos, abogado y médico; él, filósofo por formación profesional. Él quería que fuera economista o abogado y javeriano. Pero ya tenía mis propias visiones del mundo por todo aquel periplo. Desde finales de los cincuenta y principios de los sesenta, en mi adolescencia, comencé a tener inquietudes literarias, artísticas e ideológicas. Por ejemplo, aquí en Bogotá desde cuarto o quinto de bachillerato 
fui asiduo concurrente a las conferencias de Marta Traba en el Museo de Arte Moderno hacia 1963 y 1964. En ese entonces ni siquiera había museo; había una idea de museo y la mayor parte de las conferencias se dictaban en un auditorio del SENA en la Av. Caracas. Allá aprendí ciertas cosas. Ya tenía aquellas inquietudes y tenía claro que la única opción que me interesaba era la arquitectura. Entonces, cuando me tocó tomar esa decisión lo hice en contravía de mi padre, lo que me significó asumir la independencia: “Hágalo por su cuenta".

Tuve la fortuna de ingresar a la Universidad Nacional. Fue el último de los exámenes de admisión y no me había inscrito en otra universidad. Es decir, tenía dos opciones: si pasaba, iba a estudiar, si no me tocaría trabajar. Lo tenía claro. Por suerte obtuve un segundo puesto en el examen de ingreso, lo que me significó 'casa y beca': me daban residencia y algún dinerito. En esa época la Universidad tenía unos beneficios muy grandes para los estudiantes: materiales, cafetería barata, enfermería... realmente era otro tipo de universidad, eso me permitió asegurarme ahí.

JB: Eso me sugiere hacerle dos preguntas: una, ¿por qué se interesa en las conferencias de Marta Traba? es decir, ¿qué lo lleva... a eso? y dos, tal vez ahí metida, a partir de esa experiencia en ese campo y en ese escenario ¿por qué Arquitectura y no digamos... ¿Bellas Artes o Música?

RP: No he reflexionado demasiado sobre eso, pero digamos que yo fui un buen lector desde niño. A partir de los 12 años leía mucho y parte de lo que me interesó fueron las cosas alrededor del arte, la música clásica y algo de filosofía. Yo era un costeño raro porque oía ese tipo de música cuando todo el mundo oía guarachas, merengues, vallenatos y rancheras. No es que no me gustaran estos géneros, sino que a mí me ha gustado mucho la música clásica. La gente decía: este tipo anda oyendo música de iglesia; la música clásica les parecía música religiosa, pues normalmente las emisoras del país en Semana Santa apagaban su programación y solamente ponían música clásica. Aquí, con algunos compañeros del Agustiniano descubrimos las conferencias sobre arte moderno, iy nos gustó! Fuimos y nos pareció interesante. También teníamos la vecindad de la Biblioteca Luis Ángel Arango (BLAA, por estos días celebrando sus 56 años). Ahí estaba, nos quedaba en la esquina del colegio, con sus salas de exposiciones y una sala de música espectacular. Entonces había algo... ¿sí? Ahora ¿por qué Arquitectura? ¿Por qué no artes? Nunca me llamó la atención el arte como carrera. Tampoco se veía como tal. La Arquitectura me parecía la única opción y... ahora que me pone a reflexionar... me gustaba y creo que lo descubrí a través de unos trabajos que el profesor de dibujo del colegio nos puso sobre perspectiva arquitectónica. En particular recuerdo un ejercicio de dibujar el edificio de Ecopetrol, el que queda aún en la 13 con 36 , aquel que es Premio Nacional de Arquitectura, tal vez el primero. Recuerdo que tuve un buen logro al hacerlo y el profesor me estimuló por el acierto. Lo que sí tenía claro es que no quería ser ni abogado ni economista, eso lo tenía supremamente claro. Siempre he tenido algo de rechazo por ese tipo de carreras. No es que no las valore, solo que me parece que es otro tipo de pensamiento.

De hecho, para prepararme para las entrevistas de la universidad revisé muchos libros y revistas en la BLAA, recuerdo algo de Mies, de Argan, Pevsner, Gropius. En especial una frase suelta de Gropius me caló muy profundo:

"Todo me interesa". 


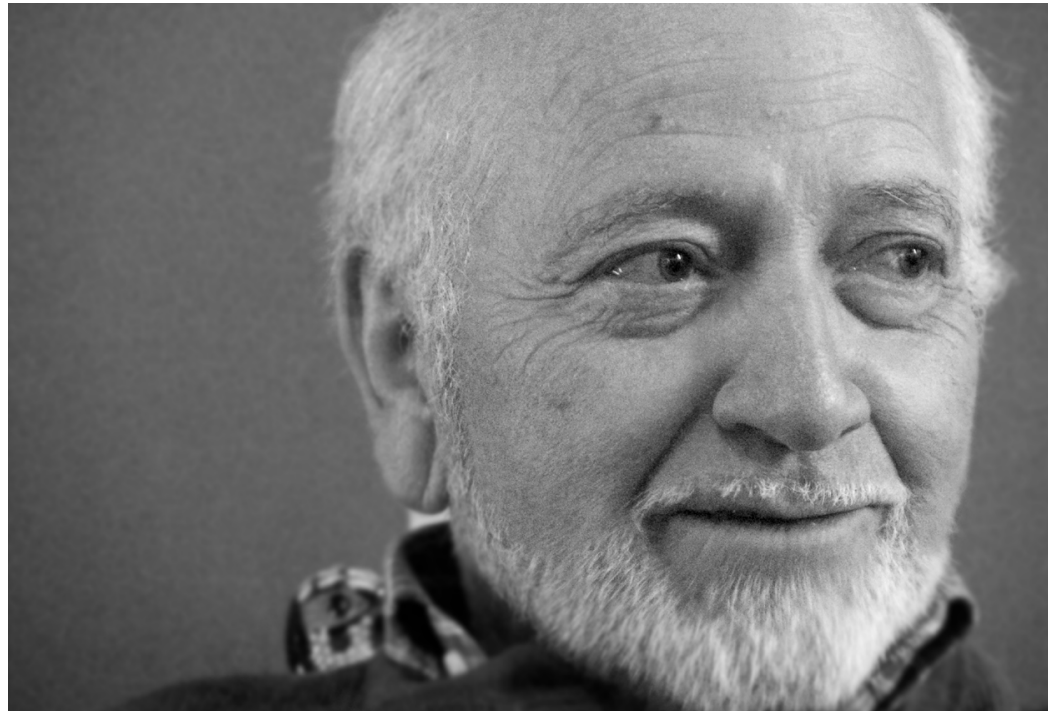

JB: ¿Qué recuerda más de esos años en los que estudió en la universidad? RP: Son tantas cosas... primero me sorprendí de que me fuera tan bien en el examen de admisión. Recuerdo que fue una jornada muy particular. No sé si todavía se practique de esa manera, pero fueron dos días y eran como ocho pruebas de distinta índole: psicológica, de biometría, de construcción... no las recuerdo todas. Nos presentamos 800 y tantos aspirantes, para seleccionar 120, creo que 80 para Arquitectura y 40 para Bellas Artes. Obtuve el segundo puesto. JB: Creo que eso sucedió en 1962, con la Reforma Patiño... RP: 1965. El hecho histórico para refrescar la fecha es el momento en que se unen Bellas Artes y Arquitectura, cuando se da inicio a la nueva Facultad de Artes (estrenamos el edificio de Bermúdez que ahora está para demoler)... JB: Creo que con la Reforma Patiño...

RP: No, no, la Reforma sí pudo ser en 1962, pero el hecho de integrarlas materialmente se dio luego. A mí me correspondió aquel momento en que se juntan realmente. Fue, además un momento también muy particular ¿no? JB: Claro, porque antes Arquitectura era una Facultad suelta...

RP: Independiente y Bellas Artes era otro mundo. Incluso las estructuras académicas eran muy disimiles. Ese año fue la primera vez que ingresamos un grupo que iba para ambas carreras. Aunque la gente había seleccionado lo que quería, los procesos eran más o menos iguales al inicio... sobre todo el proceso de ingreso y el primer semestre, que creo que fue muy parejo. Ahora: ¿qué recuerdo?... para mí fue una experiencia extraordinaria. Primero encontré un clima de libertad y de oportunidades que no había tenido en los colegios, excepto en el de la Libre. Segundo, había resuelto mi problema de sobrevivencia en las mejores condiciones: tenía residencia y manutención, no dependía de nadie. Después, a partir de eso, muchas oportunidades vinieron. Estando ahí, en la universidad teníamos un lote grandísimo, que luego fue el predio donde se amplió el edificio de Arquitectura. Ahí los primíparos jugábamos béisbol. Como yo era el único costeño del grupo, era el capitán del equipo, eso lo hacíamos en los ratos libres... se hacía la 'recocha'.

También me vinculé al Coro de la Universidad: una experiencia lindísima. Y al teatro universitario. Participé un poco de MUNIOPROC, un movimiento de
Figura 2. Rómulo Polo. Archivo fotografía: Bibiana Peña 
Figura 3. Rómulo Polo. Archivo fotografía: Bibiana Peña

5. MUNIPROC sigla de Movimiento Universitario de Promoción Comunal, era un proyecto orientado por Camilo Torres, sacerdote bogotano, promotor de la Teología de la Liberación en Colombia y junto con Orlando Fals Borda vinculado con el nacimiento del programa de Sociología en la Universidad Nacional, de la que fue, además, capellán.

6. Músico colombo-francés, considerado el primer clavecinista sudamericano (Wikipedia).

7. Considerados los primeros grupos de rock colombiano.

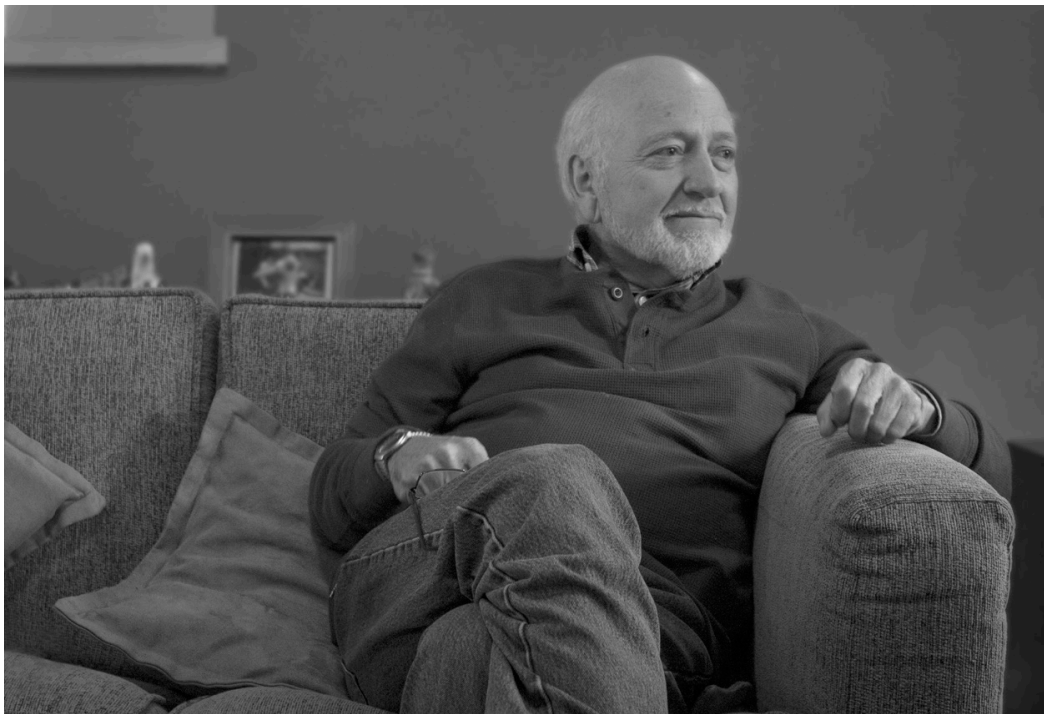

orientación social, de servicio a la comunidad. 5 Organizamos un grupo que la gente aún recuerda: se llamaba Punto 8 , lo creamos muy rápidamente, yo fui como el... presidente. No era tan formal, en realidad era un grupo pequeño y organizábamos actividades culturales en la facultad y la universidad. Cosas tan chéveres y tan raras como aquel concierto del maestro Rafael Puyana ${ }^{6}$ para la Universidad Nacional que se terminó dando en el Teatro Colón, puesto que los auditorios de la universidad eran deficientes. Eso terminó en una fiesta maravillosa en su casa, en Teusaquillo, con la gente del Coro y otros de la Nacional. Organizamos otras cosas como la primera fiesta rock que se hizo en la Nacional con los Speakers, los Flippers y otro grupo cuyo nombre se me escapa ${ }^{7}$ y otras fiestas y actividades para los primeros 30 años de Arquitectura. El dinero que recogimos fue para la Sala de Música de la Facultad. Promovimos una 'huelga' contra la terrible enseñanza que teníamos de las matemáticas: yo sufrí mucho con eso. Hacíamos las bienvenidas de los primíparos y exposiciones de trabajos. ¡Ah bueno!, hicimos un evento grandioso: la primera y única Semana Le Corbusier, con diversas actividades alrededor de su legado. Creo que fue en 1966, para conmemorar el primer aniversario de su muerte. En la Facultad había profesores especialistas en ese tema, en particular el arquitecto Hernando J. Camargo Quijano. Nosotros hicimos el trabajo, él fue nuestro inspirador y asesor. Esa semana hubo conferencias (por ejemplo, de Otto de Greiff: El Poema electrónico de LC y el Pabellón de Bruselas), con participación de Germán Samper, de otros arquitectos que habían trabajado con Le Corbusier, como Reinaldo Valencia... Bueno, ahora tampoco los recuerdo a todos. Rogelio Salmona no estaba en ese momento. Se hicieron conciertos de música electrónica... o sea, una actividad de una semana intensa, hecha por estudiantes... fueron experiencias estupendas. Por su parte la del teatro fue una época maravillosa... sobre todo el teatro universitario. Ahí estaban personajes como Carlos Duplat, Carlos Perozzo, Alberto Castilla, que era un español estupendo. Más adelante, abril de 1967, cuando ya trabajaba en Artesanía de Colombia, aprovechando ambos vínculos institucionales, con Punto 8 organizamos la primera exposición de Artesanías en el Museo de Arte Moderno, apoyados con entusiasmo por Marta Traba, quien era su directora. El museo ya funcionaba en uno de los edificios de la entrada de la universidad, por la Calle 26. Como mencioné antes a ella 
la conocía y... había sido, además, una de mis profesoras de Historia del Arte. El ambiente de la facultad era muy chévere. No tengo más que afecto por esos recuerdos, compañeros y profesores.

JB: ¿Usted habló de MUNICIPROC?

RP: MUNICIPROC fue un grupo de gente de la universidad que tenía actividades de proyección social. Íbamos a los barrios a ayudar a construir droguerías, puestos de salud, escuelas, etc. Detrás de eso estaba Camilo Torres... era la época de Camilo: una época dura y compleja, pero inolvidable.

Por otra parte, alcancé a tener en esos años una experiencia radial... Mi hermano era locutor en Emisoras Nuevo Mundo. Algún día decidieron tener una franjita universitaria los sábados en la mañana. Entonces él propuso: “Mi hermano tiene inquietudes", y terminé haciendo un mini programa radial sobre la vida universitaria. Se grababa como el jueves o algo así. Yo escribía un guioncito y leía. Con ocasión de una actividad de protesta en la Nacional, quizás contra la visita a la universidad de Carlos Lleras, ${ }^{8}$ un embajador o representante de alguna agencia norteamericana, se armó la furrusca más tremenda. Fue la primera vez que el ejército invadió el campus de la universidad. Yo me sentía en la obligación, no solamente de informar sobre eso, sino de protestar. En la emisora me dijeron: “¡Eso no se puede hacer aquí! ¡Hasta aquí llegó!”, después de unas cinco o seis emisiones.

JB: ¿Mientras tanto usted trabaja en paralelo con Artesanías de Colombia? RP: Con las cosas dichas ya le conté que tenía un cierto perfil activo en la facultad: era una persona que me movía. A mediados de la carrera, estoy hablando de finales del año 1966, me crucé en la escalera con Dicken Castro, ${ }^{9}$ quien ya 'me distinguía', como dicen los boyacenses. Él me dijo: '¡Rómulo!'; le dije: '¿a la orden, maestro?'... (creo que le decíamos Dicken o maestro...)

JB: ¿Él ya había sido profesor suyo?

RP: Profesor de Diseño Básico, que fue una experiencia muy especial, también. Me dice: "Rómulo, necesito dos diseñadores"... "Espere, maestro, voy a buscar el otro"... fue mi reacción. Fui, efectivamente a buscar al otro, Hernán Lozano (fallecido hace pocos años) por quien mantengo un aprecio muy particular. Éramos buenos amigos... él era muy talentoso... Le dijimos: “¡Aquí estamos!”. Dijo: "Vayan a una entrevista en Artesanías de Colombia". Ni siquiera sabía qué era eso. Fuimos a la entrevista con un gringo, quien nos preguntó lo general, en inglés norteño: “Qué hacen? ¿Qué han hecho?”. Con nuestro perfil de estudiantes a media carrera en Arquitectura, ¿qué habíamos hecho?: ocho o diez proyectos. Escuelas, vivienda, principalmente. Pues, ¿qué? Llevamos los planos y perspectivas de esos proyectos. A William Newman, que así se llamaba este señor, le parecieron bien. Sin embargo dijo: "Por favor... traigan mañana unos bocetos de unas sandalias, a ver cómo es su imaginación". Nos fuimos a hacer los bocetos: hice $160 .$. Hernán hizo 300 y pico... él tenía una habilidad expresiva... era realmente ¡talentoso! Newman quedó asombrado y de inmediato nos dio el trabajo. Nosotros le dijimos que estábamos estudiando. Nos dieron horarios muy flexibles y no tuvimos que interrumpir prácticamente nada. Íbamos y veníamos. Claro, éramos buenos trabajadores, eso sí, y buenos estudiantes. Hernán, que era muy romántico dijo: “Aquí voy a aprender inglés... con eso me siento retribuido" y dije: "No, yo si quiero que me paguen" [risas]. Nos dieron un sueldo inicial de 980 pesos, muy bueno para unos aprendices; una fortuna para un estudiante. Comenzamos a trabajar en diciembre de 1966, más o menos, y progresivamente nos fuimos entusiasmando con el tema. Yo tenía la ventaja de tener motoneta, una Vespa roja que le compré a Newman, recién entrado;
8. Sigla de Movimiento Universitario de Carlos Lleras Restrepo fue presidente de Colombia entre 1966 y 1970, quien fuera el tercero el tercero al turno en el Ilamado Frente Nacional (1958-1974).

9. Dicken Castro es considerado uno de los pioneros del ejercicio del Diseño Gráfico en Colombia. Estudió Arquitectura en la Universidad Nacional de Colombia, se posgraduó en la Universidad de Oregon-Eugene en Estados Unidos y en Baucentrum de Rotterdam, esto último en 1960. 
10. Jaime Gutiérrez es considerado como el primer diseñador industrial colombiano. Estudió Fine Arts en Chouinard Institute en Estados Unidos durante los años cincuenta y luego Diseño Interior en Belmonth Adult School, también en EUA e Ingeniería de Muebles en el Instituto Lathy de Finlandia.

11. Daniel Samper es uno de los periodistas más prolíficos en Colombia. Por su parte, Ernesto Samper fue Presidente de Colombia entre 1994 y 1998.

12. Alfred B. Girardy fue un diseñador suizo nacido en 1916, con formación inicial en la Bauhaus y graduado en Pratt Institutte en Nueva York. Por lo determinado hasta ahora, Girardy por lo menos, estuvo involucrado en procesos de institucionalización del diseño en Japón, Taiwán y Colombia durante los años cincuenta. De hecho, es uno de los responsables de la conformación de Artesanías de Colombia en 1964. entonces mi movilidad era sencilla y eficaz. Artesanías de Colombia quedaba cerca de la universidad, detrás del Club Militar, por la Av. de las Américas.

Más tarde la empresa nos apoyó para hacer unos cursos con Jaime Gutiérrez Lega ${ }^{10}$ que montó en la Universidad de los Andes, en 1967 y 1968. Después a mí, un nuevo gerente me mandó a hacer además un curso de Relaciones Públicas en esa universidad, porque vio que escribía, que hacía informes y que me gustaba investigar. Ese curso lo hice con Andrés Samper, el padre de los Samper, Daniel y Ernesto. ${ }^{11}$

Todo eso nos 'encarretó' y nos llevó a montarnos en el diseño y a bajar la expectativa sobre la arquitectura, sobre todo a mí. Como me preguntaba al inicio, la arquitectura era una opción: me gusta, la amo profundamente, pero... yo estaba buscando esto que encontré de carambola, el diseño.

JB: ¿De qué se trataba el trabajo? ¿Para qué los contrataron?

RP: En Artesanías de Colombia se había creado un Departamento de Diseño que para mí marca el nacimiento institucional del diseño en Colombia, desde 1964. ¿Por qué lo digo? Porque se trató de una institución pública que destinó unos recursos binacionales para realizar una actividad específica de diseño industrial en un campo de aplicación particular: la artesanía, a nivel nacional y de modo más o menos sistémico. ¿Con quién? Con especialistas gringos, contratados por la AID (Agencia para el Desarrollo Internacional, del Departamento de Estado de los Estados Unidos). A nosotros nos correspondió trabajar bajo la dirección de William Newman, diseñador, ceramista, quien llegó a mediados de 1965. Él venía de la Universidad de Syracuse. La actividad de Diseño en Artesanías de Colombia, en estricto sentido, había sido iniciada por Alfred Girardy ${ }^{12}$ como asesor externo, inicialmente contratado por Piñata Party (a su vez contratada por el Departamento de Estado norteamericano) unos dos años antes (posiblemente en 1963), con ayuda de Ruth Cepeda, arquitecta de Popayán. Con ellos trabajaron, además, algunos Cuerpos de Paz. Cuando Girardy se enfrenta con algunos expertos en comercialización de la AID (en buena parte jubilados de Sears) por asuntos de enfoque del programa, sale y termina su contrato, dándole entrada a Newman. Cuando llega Newman es cuando nos llaman a nosotros, Hernán y yo. JB: ¿Usted sabe por qué Dicken sabía qué necesitaba Artesanías de Colombia? RP: Dicken ha sido un hombre bien conectado. Con seguridad era amigo de Felipe Zapata, el gerente de esos años, quien recurrió a él. Dicken ha sido persona de buenas relaciones.

JB: ¿Quién era Felipe Zapata?

RP: Fue el gerente de Artesanías de Colombia en ese instante, más o menos hasta inicios de 1968, cuando lo reemplaza Federico Echavarría. El equipo de diseño y desarrollo estaba formado en Bogotá por William Newman y Carl Erickson, diseñador industrial de Pratt y Cuerpo de Paz y se apoyaba en algunos otros Cuerpos de Paz que estaban en varios sitios artesanales del país, que se encargaban de los aspectos de desarrollo. En su mayor parte eran diseñadores o especialistas en técnicas de artesanía, necesitaban formar gente local que se entrenara en lo que hacían todos ellos. Hernán y yo, empezamos dibujando y muy rápido fuimos asumiendo los procesos de Diseño y desarrollo, orientados y estimulados por Bill y Carlitos, que así los tratábamos.

Fue un aprendizaje inigualable de diseño industrial, con verdaderos especialistas y problemas reales. Tal vez no tuvo la formalidad académica... pero, por un lado trabajábamos con verdaderos diseñadores, no con arquitectos que creían entender el diseño (con esto no quiero decir nada malo) y, a la vez, con 
productores de verdad; los artesanos. Desde luego hay muchos problemas de fondo en todo eso, muchos mitos y falsedades, pero son temas de otros debates, cuyas vertientes alcanzamos a debatir y confrontar desde entonces. Muchos de esos problemas y desenfoques aún persisten e incluso se han ampliado, pero eso será otra tarea. Hay diversos artículos míos sobre el tema... JB: Usted dijo Universidad de Syracuse... Se me acaba de conectar... jahí estaba Pulos!

RP: No sé si en esos años estaba Arthur Pulos o posteriormente... es posible. Conocí a Pulos en los años ochenta; tuvimos unas buenas conversaciones, pero en la perspectiva de los temas asociativos, en los inicios de ALADI.

JB: A principios de esa década, los ochenta, él fue presidente del ICSID (International Council of Societies of Industrial Design).

RP: Cuando era presidente, no; lo conocí cuando era past-president, el presidente de ese momento era George Nelson. También lo conocimos, ambos estuvieron en Medellín en 1981.

Pero bueno, regresando a la experiencia de Artesanías, progresivamente nosotros íbamos teniendo que viajar más a los campos. Era un trabajo que hacíamos los fines de semana. Sobre todo los que quedaban a distancias razonables... y eventualmente íbamos a los otros sitios. Progresivamente fue cada vez más intenso. Cuando pasa el primer año larguito, Bill se va, y el otro americano, Carlitos, no podía desempeñar cargos por alguna razón de su vínculo como Cuerpo de Paz y finalizaba también su servicio; entonces Felipe Zapata, el gerente, me nombró jefe del departamento. No lo menciono por vanagloriarme sino porque es un hecho: fui el primer colombiano jefe de esa oficina. JB: ¿Se acuerda del año? RP: Finales del 1967, posiblemente 1968. Yo estuve hasta finales de 1968 en Artesanías de Colombia.

JB: Girardy ya no estaba...

RP: No, Girardy ya había salido desde finales de 1964 o principios de 1965. Yo llegué a conocer a Girardy solo hasta finales del 1968, cuando me estaba retirando de Artesanías, por diferencias de fondo con el gerente de entonces, Federico Echavarría...

JB: ¿Qué diferencias...?

RP: Su pragmatismo y la mentalidad que promovía: "Hay que producir, producir, producir"... Un día le dije "pero es que hay que conocer, conocer, conocer" y eso implicaba investigar. Entonces él me dijo pero "¿qué clase de diseñador es usted que no quiere diseñar?" Le respondí que yo sí quería diseñar pero sin violentar unas cosas que tienen un valor y que apenas estábamos entendiendo. Nadie sabía de artesanías aquí, y pocos conocían a los artesanos... En síntesis, descubrí que no se podía diseñar sin investigar y quería hacer un trabajo serio. Como el trabajo que él priorizaba era más como relacionista, entonces pensé que era el momento de irme.

JB: Intento hacerme una imagen cuando dice que con Hernán tenían que salir al campo... podría describir un poco más lo que hacían en ese trabajo. ¿Qué observaban?, ¿a qué le ponían atención?, ¿qué grandes anécdotas recordaría? RP: Creo que en alguna parte mencioné eso... Es decir, ¿cómo comenzamos trabajando allá? Pues inicialmente como dibujantes. No éramos unos auxiliares de 'tome y dibuje esto': nos ponían a crear... Decían Bill Newman o Carl Erickson: "Mire, tome estos patrones aquí y diseñe alfombras... entonces, cogíamos el sistema que ellos indicaban... proyectábamos las alfombras y ellos decían: “Esto no, esto sí, aquí esto, aquí aquello..." Lo que hace un 
director de oficina... Después teníamos que ir con los artesanos a desarrollar esas cosas, a ver los problemas reales que había, si los telares servían, si los tejidos y las lanas o los hilos eran apropiados... todo un proceso, porque con los artesanos hay que lograr comunicarse. Claro, mucha gente llega y les deja un dibujo o les lleva una fotografía, pero nosotros estábamos en otro plan: hacer con ellos las cosas, o que ellos la hicieran bajo nuestra 'asesoría'. Ahí es donde digo: debemos ser respetuosos con esas personas, que también son creativas y tienen un bagaje muy importante. Es decir, no es suficiente 'inventar' cambios en las cosas... hay un problema de honestidad en el trabajo... ¡Rico inventarse vainas! y poner a 'esos indios' (así les decía mucha gente) a hacer lo que se les pidiera. En palabras de ahora, estaríamos hablando de co-creación y trabajo participativo (o algunas de esas carretas que están de moda). Eso lo vivimos en la realidad en ese momento, ese era el trabajo... Teníamos apoyo de los Cuerpos de Paz en varios pueblos, no en todos. En general ellos eran especialistas en temas técnicos; por ejemplo, ceramistas, expertos en tejeduría y distintas cosas, pero también eran diseñadores en su mayoría, profesionales egresados de distintas universidades norteamericanas, sin mucha experiencia pero con conocimiento; entonces, con ellos colaborábamos también, ¿sí?... Ese era el trabajo fundamental.

Ahora, la visión inicial de los gringos era darle al artesano el dibujo para que él lo realizara. En la visión que comenzamos a desarrollar (con Hernán) planteábamos un problema distinto: cómo dar margen a la expresión propia, respetando los valores, etc. Mire usted, Juan, en el plegable de la exposición que se montó en el Museo de Arte Moderno sobre artesanías, David Consuegra destaca como imagen la muestra el 'León de Ráquira', diseñado por Bill Neumann... jel león de Ráquira! ¿Sí? Es algo inconsecuente que evidencia nuestro desconocimiento de la expresión popular auténtica. Ahí está la evidencia. Como caso de diseño fue interesante, en el sentido experimental, porque fue la primera vez que se trató de mezclar en un producto la cerámica con otros materiales nativos... (un cuerpo de león en cerámica, con la cabeza aplanada... un león en el estilo de cómic americano, con un collar hirsuto, anudado en fique, para simular la melena)... Como idea, interesante; como solución, errónea. David toma eso y lo usa ingenuamente como imagen de la exposición. Aún no teníamos un sentido crítico como para hacer esas diferencias; de hecho, yo estuve comprometido en el desarrollo del 'León de Ráquira'... [risas] Para ese museo fue algo insólito (iy, más, que Marta Traba lo aceptara!, porque ella era una persona muy profunda, muy dura, o sea, un verdadero filtro en temas artísticos, pero no artesanales, creo). No hubo dificultad, fue una exposición bonita en su momento. Por otra parte, tal vez en 1967 , tuvimos la oportunidad de recorrer el país. Hernán lo hizo hacia el sur, yo hacia el norte. Recorridos de exploración y recolección. Fui desde Barrancabermeja hasta la Guajira 'arriba', viajando en 'chivas', jeeps, aviones, lanchas... Una aventura. Fui a la Sierra Nevada y toda esa región, buscando 'cosas artesanales', porque esa era la misión... El producto de ese trabajo lo llevó Artesanías a una exposición en la Casa de Colombia en Nueva York. Muchas otras experiencias de orden técnico y humano... anécdotas habrían muchísimas ¿no?

\section{Referencias}

Marx, K. (2003). El 18 Brumario de Luis Bonaparte. Madrid: Fundación Federico Engels.

Mills, W. (2003). La imaginación sociológica. México: FCE. 